\title{
EDUCAÇÃO - UM OLHAR PARA A TRANSFORMAÇÃO
}

\author{
Benedita Neire A.de Magalhaes ${ }^{1}$ \\ Reybia Bueno Ramos ${ }^{2}$
}

RESUMO: O presente artigo tem como intenção a transformação da escola por meio da reflexão acerca da visão de Marx sobre a educação e as suas possíveis interpretações a partir de duas correntes marxistas distintas: sendo a primeira teoria a da reprodução e a segunda teoria a da resistência. Diante das interpretações sobre o pensamento educacional de Marx, o texto reconhece que a Escola não é apenas um espaço de reprodução ideológica na sociedade capitalista, mas é também, por contradição, um espaço de luta e resistência ao pensamento hegemônico dominante.

Palavra-chave: Transformação. Educação e resistência. Marxismo.

ABSTRACT: This article intends to transform the school by reflecting on Marx's view of education and its possible interpretations based on two distinct Marxist currents: the first theory being that of reproduction and the second theory that of resistance. Given the interpretations of Marx's educational thought, the text recognizes that the School is not only a space for ideological reproduction in capitalist society, but it is also, by contradiction, a space for struggle and resistance to the dominant hegemonic thought

Keyword: Transformation. Education and resistance.

\footnotetext{
Graduada em História pela Universidade Federal de Mato Grosso e Pedagogia pela Faculdade Afirmativo. Pós-graduada em Gestão Escolar pela UFMT, Educação. Metodologia e Didática do Ensino de Fundamental e Médio do Ensino de História pela UFMT. Pós-graduada em Atendimento Educacional Especializado pela Faculdade Faveni. Professora efetiva da rede Estadual de ensino e da rede Municipal e já atuou como Coordenadora da rede particular. Coordenadora de formação da SMEC/Jaciara. Orientadora do Programa Alfabetização na Idade Certa. E atuou como Secretária Municipal de Educação do Munícipio de Jaciara-MT. Mestranda no curso de Pós-Graduação em Educação pela Universidade Federal de Mato Grosso, na Linha de Pesquisa - Educação em Ciências e Educação Matemática. E-mail: jacneiremagal@gmail.com.

2 Graduada em Pedagogia pelo Instituto Superior de Educação de Ibituruna-ISEIB e em Letras/Literatura/Inglês pela Universidade Federal de Mato Grosso. Pós-graduada em TGD-Transtorno Global de desenvolvimento pela Faculdade Única-MG. Professora efetiva da rede Estadual de ensino do município de Jaciara-MT. Estudante como aluna especial na Pós-graduação em Linguagem pela UFMT. E-mail: reybiabuenozorg@gmail.com-
} 


\section{INTRODUÇÃO}

Analisar a educação numa perspectiva marxista não é tarefa fácil, porque exige a localização da relação sujeito-objeto como um eixo central, partindo do princípio de que a educação é inerente a quaisquer sociedades, seja ela civilizada ou primitiva. É um elemento de resistência, uma forma de sobrevivência de todo ser humano em razão do homem não se constituir um ser estático, mas vivo, transformador do ambiente em que está inserido por meio da apropriação da consciência e a experiência. Diante dessa realidade, deve-se perscrutar o papel da escola no modo de produção capitalista e indagar se a instituição escolar aparece como uma engrenagem ou meio de transformação ou reprodução para o capital.

Marx parte do pressuposto da contradição do próprio capitalismo dentro da relação entre capital e trabalho, da superestrutura e infraestrutura, onde a mais-valia aparece como a base da exploração da mão de obra do homem que produz. A educação para Marx está atrelada as forças produtivas advinda do trabalho. O papel da educação dentro do materialismo histórico surge como instrumento de desalienação do proletário no sentido de ele enxergar a sua condição de explorado. É justamente aqui que surge a escola como instrumento de reprodução.

Nesse sentido, Marx propõe uma educação libertadora que tem como função principal, romper através da revolução proletária, com a opressão burguesa detentora dos meios de produção (capital, riqueza), com o fim último de levar à uma sociedade justa e igualitária. A educação para Marx é eminentemente social e emancipadora de todo ser humano. A luta de classes é permanente entre o opressor e o oprimido, somente a educação é capaz de conduzir o homem à uma sociedade mais justa e fraterna dentro da visão marxista.

\section{O MARXISMO E A EDUCAÇÃO}

Karl Marx não ficou alheio ao fenômeno educacional dentro do modo de produção capitalista, olhando com desconfiança a forma como ela foi construída dentro 
da estrutura e superestrutura da sociedade capitalista, ele não via com bons olhos a educação instituída dentro do Estado-Nação burguês, sem fugir do foco da concepção filosofia. Nesse aspecto, Karl Marx vê todo processo educacional como mais um elemento de alienação do indivíduo em virtude de a escola ser uma faca de dois gumes nas condições materiais de existência de todo o ser humano, portanto ela não deixar de ser mais um instrumento da luta de classe entre quem detém o meio de produção e o oprimido. Nesse contexto, então para que serve a escola dentro do modo de produção capitalista? Para alienação ou libertação do indivíduo?

Para Ghiraldelli Junior,

[...] as ideias de Marx, conta-se tipicamente, a percepção do mundo social pela categoria de classes, definida pelas relações com os processos econômicos e produtivos, a crença no desenvolvimento da sociedade além da fase capitalista através de uma revolução do proletariado. $\mathrm{Na}$ prática, o marxismo é um comprometimento com as classes exploradas e oprimidas, e com a revolução que deverá melhorar sua situação. (GHIRALDELLI, 2008, p. $85)$.

Diante de todo o arcabouço marxista, a educação se constitui também numa arma para transformar e não para reproduzir para o capital. A chamada fase da ditadura do proletariado, onde a classe proletária toma consciência da sua realidade de classe oprimida, a educação aparece como um instrumento poderoso da Revolução, bem como a tomada de poder das mãos da burguesia.

Enguita esclarece que:

Um dos debates mais insistentes e repetidos em torno da instituição escolar, sempre foi à questão de evidenciar o seu papel, que era reprodutor ou transformador, isto é, se contribuía para conservar a sociedade ou mudá-la. Até certo ponto, era trivial, pois, por um lado nenhuma sociedade poderia substituir sem formar seus membros em certos valores, habilidades, etc. e, por isso, toda educação é reprodutora; mas ao mesmo tempo, nenhuma sociedade atual seria, sem a escola, o mesmo que chegou a ser com ela, e, por isso, toda educação é transformadora. (ENGUITA, 2004, p.13)

A educação é transformadora ou reprodutora independentemente de o indivíduo estudar ou não, porque tudo vai depender do grau de consciência de classe de cada pessoa, considerando o meio cultural, e o nível da sua alienação. Por isso que muitos podem ser PHD em conhecimento, mas isso não significa que tal indivíduo não seja 
alienado ou reprodutivo. Marx acreditava que a educação era parte da superestrutura de controle usada pelas classes dominantes. Por isso, ao aceitar as ideias passadas pela escola à classe dos trabalhadores (que Marx denominava classe proletária) cria uma falsa consciência, que a impede de perceber os interesses de sua classe. Dessa forma, Marx concebia uma educação socializada e igualitária a todos os cidadãos.

Todavia, todo e qualquer processo relacionado com a educação é lento, o que induz a persistência e luta dos ideais, pois somente então poderá haver a concretização do saber teórico com a prática, o que será motivo de muitas contradições e ao mesmo tempo de aprendizagem, e isto, têm início em cada um de nós.

A educação tende a ser considerada como elemento conservador da sociedade, mas por ser um instrumento formador e de expressividade em qualquer tipo de sociedade, não pode e nem deve ser vista dentro de limites fechados, analisada independentemente do contexto sócio-político e econômico em que vive tal sociedade. Deve ser encarada como parte integrante e necessária de um sistema, já que é usada de acordo com seus interesses.

Pode-se dizer que a educação é um reflexo da política adotada em um país e do interesse desse país em coordená-la, é um dos maiores instrumentos de dominação em massa dentro de um sistema, perdendo apenas para a mídia que é acessada por muito mais pessoas do que o sistema educativo.

\section{EDUCAÇÃO BRASILEIRA DIANTE DO PENSAMENTO DE KARL MARX NOS DIAS ATUAIS}

Essa luta de interesse se manifesta no Brasil atualmente na luta entre as forças progressistas e o atual projeto de extrema direita que atende os interesses da elite econômica representado na pessoa de Jair Bolsonaro, onde aqueles defendem um modelo de educação humanística e voltado para o social em direção à inclusão das minorias, enquanto este defende um modelo de educação extremamente conservador estruturado nos valores morais de família e religião que também sempre foram instrumento de reprodução de capital. Expondo as vísceras de uma educação que atende 
claramente os donos do capital. O brasileiro só conseguirá distinguir o seu verdadeiro lugar na pirâmide da classe social trabalhadora, a plebe, através da emancipação intelectual e política. Aí descobrirá que todas riquezas provem do trabalho, logo a classe trabalhadora que deveria apropriar-se da riqueza e não o contrário.

O projeto de educação da extrema direita no Brasil se opõe a todo projeto social e inclusivo. Temos como exemplo o ataque de Bolsonaro e seus asseclas à Karl Marx e Paulo Freire. Por que recentemente Bolsonaro chamou Paulo Freire de energúmeno? Ora, porque toda a obra educacional de Paulo Freire foi concebida e posta em prática como uma opção pelos pobres, pelos excluídos, pelos marginalizados. Por esse motivo representa um projeto de manifesto antagonismo com o projeto que anima o governo neoliberal de Bolsonaro, que representa a opção pelos ricos, pelos afortunados, pelos opressores, pelos espoliadores dos sonhos e da vida de milhões de brasileiros. No caminho de destruição, aberto pela eleição de Bolsonaro, além da supressão dos direitos trabalhistas e previdenciários da classe trabalhadora, da supressão ou degradação das políticas públicas de inclusão social, o desgoverno atual avança, feroz, cínica e destrutivamente sobre aquela que poderia fornecer elementos críticos para resistir à destruição em curso, que é a Universidade Pública brasileira. Daí a razão do ódio do projeto da extrema direita contra Marx e Freire.

Gramsci (1968) destacou a importância da criação de uma "escola humanística", que desenvolvesse a inteligência e a formação consciente; uma escola aberta defato para conquistar a liberdade. A hegemonia é conseguida, conforme Gramsci,por meio de uma luta "de direções contrastantes, primeiro no campo da ética,depois no da política”. Para Gramsci, cada grupo social básico, com papel determinantena produção, produz seus próprios intelectuais, ditos "orgânicos". Portanto, a classe burguesa, ao desenvolver-se no seio do antigo regime, origina não apenas o capitalista, mas também uma série de "intelectuais. Tais intelectuais são os responsáveis pela nova configuração do Estado e da sociedade. Seriam os "funcionários da superestrutura" que acabariam por amoldar o mundo à imagem e semelhança da classe dominante. 
Gramsci não era um especialista em educação, não era filósofo nem um sociólogo, era apenas um ativista político que enfrentou a prisão, mas deixou uma contribuição tão importante no campo da educação social e libertadora que aproximou das ideias marxista de um modelo de educação social e humanística. Ele dizia que a tendência democrática de escola não pode consistir apenas em que um operário manual se torne qualificado, mas em que cada cidadão possa setornar governante. É um ideal que encanta os olhos de qualquer apaixonado pela educação social e inclusiva.

O que nos fascina em Gramsci é que a democracia foi uma questão fundamental para este pensador, mas destacou o papel da escola na formação do cidadão consciente, proporcionando a partir desta formação uma democracia com o povo e não para o povo. Ainda hoje seu pensamento, suas teorias podem se aplicar para entendermos nossos problemas na educação, na política e para tentarmos agir de forma consciente.

Voltando novamente à realidade da educação brasileira no que se refere à experiência marxista, no Brasil as obras de Marx começaram a ser mais divulgada depois da fundação do Partido Comunista do Brasil, isto é, a partir de 1930 em plena gênese da era Vargas. Ainda nesta época o educador Paschoal Lemme considerado marxista, publica um trabalho sobre o ensino dos adultos e organiza cursos para operários no Distrito Federal.

Neste documento pode ser visto algumas características do marxismo que o influenciava. Contudo para Lemme "argumentou que só algum tempo mais tarde, principalmente, a partir de 1933, influenciado pelos acontecimentos político-sociais que vinham se desenrolando no mundo e no país, é que se interessou mais de perto pelo estudo dessas questões, ou seja, as obras de Marx”. (1988: p. 213)

Vale salientar, os pressupostos do pensamento neoliberal estão povoando a educação nacional e disputam uma nova configuração educacional, especialmente no que diz respeito às políticas de formação profissional.

Para Paulo Freire (1967), a realidade o que ele via eram os homens oprimidos, direcionados, passivos, comandados pelo poder de uma minoria, que inventam mitos 
para massificar e conseguir impor suas ideologias, que cada vez mais negava os direitos à educação à maioria da população e os oprimiam:

Uma das grandes, se não a maior, tragédia do homem moderno, está em que é hoje dominado pela força dos mitos e comandado pela publicidade organizada, ideológica ou não, e por isso vem renunciando cada vez, sem o saber, à sua capacidade de decidir. Vem sendo expulso da órbita das decisões As tarefas de seu tempo não são captadas pelos homens simples, mas a ele apresentadas por uma "elite" que as interpreta e lhas entrega em forma de receita, de prescrição a ser seguida. E, quando julga que se salva seguindo as prescrições, afoga-se no anonimato nivelador da massificação, sem esperança e sem fé, domesticado e acomodado: já não é sujeito. Rebaixa-se a puro objeto. Coisifica-se. (FREIRE, p.43, 1967)

Portanto, para Freire a luta é para que o homem seja livre e parecido com a da realidade histórica, que só se dará a partir do homem acreditar em si e do reconhecimento do oprimido em relação a si mesmo.

\section{O MATERIALISMO HISTÓRICO E DIALÉTICO DE KARL MARX E A EDUCAÇÃO}

Sabemos que não teve como pretensão sistematizar uma teoria sobre a educação. Ainda assim, é possível encontrar apontamentos do filósofo sobre o tema em alguns extratos intermitentes ao longo de sua obra. Os elementos de uma concepção marxista de educação começam a surgir somente na década de 1840 , em muitas obras de Marx e Engels.

Para Marx, a educação deve estar integrada ao trabalho produtivo desde a infância. Isso não deve ser entendido como apologia à exploração do trabalho infantil. É que para esse filósofo, o homem constrói sua humanidade em suas práxis no mundo, por meio do trabalho. Ao transformar o mundo, também se transforma. Pode-se dizer que o trabalho é a categoria fundante da humanização, para Marx, e também um “princípio educativo” (LOMBARDI, 2008). Nessa perspectiva, a educação associada ao trabalho produtivo, tem a função de reintegrar o trabalho intelectual ao trabalho manual 
(concepção e execução), separados pela divisão social do trabalho nas sociedades capitalistas.

A intenção é que o trabalhador tenha uma compreensão integral do processo produtivo e não esteja alienado do mesmo. Isso também pode ser visto como uma possibilidade de superar a ruptura entre a ciência e o trabalho, típica da produção industrial. Lombardi destaca que a teoria marxista entende que:"com o trabalho produtivo, a educação deveria possibilitar o acesso aos conhecimentos historicamente produzidos pela humanidade, em seus aspectos filosófico, científico, literário, intelectual, moral, físico, industrial e cívico”. Lombardi (2008, p. II)

Marx reconhece, porém, que tal educação só é possível em uma sociedade onde sejam extintas a propriedade privada dos meios de produção e a divisão social do trabalho, típicas do capitalismo, ou seja, em uma sociedade comunista.

\section{CONSIDERAÇÕES FINAIS}

Com base nas ideias de Marx pode-se inferir que educar é um desafio social. Assim sendo, esta prática pode tornar-se um instrumento mobilizador para com a situação atual em que vive a população. É preciso superar uma sociedade voltada à produção aos bens de consumo, que despreza a natureza humana e histórica. O ser humano precisa ser respeitado em sua totalidade, em suas potencialidades, modo de expressão e de pensar, ter o direito a uma educação igualitária baseada em princípios $\begin{array}{lllll}\text { democráticos não } & e & \text { nescravidão. }\end{array}$ Lembrando que, ao invés de serem independentes das mazelas da sociedade, a escola é uma das partes integral do sistema capitalista e, como tal, seu potencial para a reforma está bastante limitado. Apenas com a reforma do sistema político e econômico o ensino poderá ter algum efeito na emancipação dos menos favorecidos. A dialética por si abre caminhos para a busca e concretização destes ideais, entretanto, é uma luta constante e necessita muita perseverança, sendo a educação uma alternativa de se elucidar tais problemas. Faz-se conveniente evoluir um pensamento e atos, pois 
somente assim o homem se sentirá capaz no que realiza. Dessa maneira, Marx contribuiu para a educação do homem moderno, em sua teoria educacional, o marxismo, mistura a teoria e a prática e apresenta aos aprendizes a necessidade crucial da atividade racional e um sentido de responsabilidade social necessário para uma existência mais humana.

\section{REFERÊNCIAS BIBLIOGRÁFICAS}

ENGUITA, Mariano F. A face oculta da escola. Porto Alegre: Artes Médicas, 2004.

FREIRE, P. Educação como prática da liberdade. I⿳亠丷a ed. Rio de Janeiro: Paz e Terra, 2019. GRAMSCI, Antônio. Os Dirigentes e a Organização da Cultura. Rio de Janeiro: Civilização Brasileira, 1968.

GHIRALDELLI JUNIOR, Paulo. Filosofia e história da educação brasileira. Barueri, SP: Manole, 2003.

LEMME, Paschoal. Memórias. São Paulo, Cortez / Brasília, INEP, v.2, 1988.

LOMBARDI, José Claudinei; SAVIANI, Demerval (orgs.). Marxismo e educação: debates contemporâneos. 2. ed. Campinas, 2008. p. oI-38. 